\title{
Mechanical Characteristic Behaviour of Medium Carbon Low Nickel Chromium Steel to General Conventional Heat Treatments
}

\author{
Devpriyo Ghosh ${ }^{1, *}$, Sarthak Nangia ${ }^{1}$, Sourav Chakravarty ${ }^{1}$, Sharwin Maben ${ }^{1}$, Satya Shankar Sharma ${ }^{2}$ \\ ${ }^{1}$ Manipal Institute of Technology, India \\ ${ }^{2}$ Department of Mechanical and Manufacturing, Manipal Institute of Technology, India
}

Copyright (C) 2015 by authors, all rights reserved. Authors agree that this article remains permanently open access under the terms of the Creative Commons Attribution License 4.0 International License

\begin{abstract}
The medium carbon low nickel chromium steel is a widely used high strength low alloy steel that provides an advantageous combination of strength, hardness, toughness and ductility for machine part members. It has been widely used for fabrication of parts like gears, cams, piston rods and shafts to name a few. This steel may be subjected to general conventional heat treatments to substantially alter its mechanical characteristics. The typical microstructure of hardened steel shows a martensitic matrix responsible for its strength and wear resistance. Before hardening and tempering, normalizing heat treatment was given to standardize the microstructure. In this study tensile, microstructure and hardness specimens were prepared and subjected to Hardening and Tempering heat treatment. The tensile strength of each specimen including the as-received was tested in an electronic tensometer. Microstructures were recorded on heat treated as well as untreated conditions. Rockwell hardness test was performed on each of the hardness specimen including the as-received one.
\end{abstract}

Keywords Heat Treatment, Hardening, Tempering, Tensile Strength, Hardness, Holding Time

\section{Introduction}

Steel is an alloy of Iron and Carbon. Carbon is present in steel in combined form like cementite. The maximum limit of carbon in steel is $2 \%$ by weight [1-4]. Alloying and heat treatment are two methods which are extensively used for controlling material properties. It has already been inferred that the steel on heat treatment can undergo morphological changes to obtain different mechanical properties.

As a tailor made process for having different mechanical properties, heat treatment has gained wide attention [5]. In the present work, an attempt has been made to study the effect of variation of process parameters such as holding temperature, holding time and type of heat treatment on the hardness, tensile properties and microstructure of medium carbon low nickel chromium steel.

An understanding of the mechanical properties of metals during deformation over a wide range of loading conditions is of considerable importance for a number of engineering applications. When discussing high strength steel, it is crucial to realize that the definition of so-called high strength depends entirely upon how the steel is to be used. These usages tend to fall into a number of different categories where different combinations of properties are required. In each of these categories, work has been carried out, to develop higher strength steels, to take the manufacturing processes, the heat treatment and the alloying technology into consideration [6]. The medium carbon low nickel chromium steel in a tempered martensitic phase has been widely used in various engineering applications, such as the fabrication of gears, shafts and piston rods due to its excellent combination of strength, ductility and toughness. The chemical composition of the investigated sample is listed in Table 1.

Table 1. Chemical Composition of investigated steel

\begin{tabular}{|c|c|c|c|c|c|c|c|c|c|}
\hline$\% \mathrm{C}$ & $\% \mathrm{Si}$ & $\% \mathrm{Mn}$ & $\% \mathrm{Mo}$ & $\% \mathrm{Ni}$ & $\% \mathrm{Cr}$ & $\% \mathrm{Cu}$ & $\mathrm{P} *$ & $\mathrm{~S} *$ & $\% \mathrm{Fe}$ \\
\hline 0.37 & 0.31 & 0.67 & 0.21 & 1.40 & 1.51 & 0.18 & 140 & 310 & $\mathrm{Bal}$ \\
\hline
\end{tabular}

* : ppm. 
Steels can be subjected to variety of conventional heat treatments like annealing, normalizing, hardening and tempering. The combination of heating and cooling operations applied to a metal or alloy in the solid state is termed as heat treatment. The high temperature phase austenite in steel has the property to transform into variety of room temperature phases like coarse pearlite, sorbite, troostite, bainite \& martensite depending upon the cooling cycle $[7,8]$. These phases may be the decomposition products like ferrite \& cementite or it may be super saturated solid solution known as martensite [9]. If the austenitic phase is cooled at a slightly faster rate, the decomposition of austenite by the eutectoid reaction takes place forming medium or fine pearlite with increased weight percentage of eutectoid mixture (pearlite). This treatment is known as Normalizing. Here the degree of dispersion of ferrite and cementite in pearlite increases to improve the machinability with finer grain size [10]. If the austenitic phase is cooled in such a way that the cooling rate is greater than or equal to critical cooling rate (CCR), the transformed phase is termed as Martensite. It is supersaturated single phase with body-centered tetragonal (BCT) structure. The BCT structure has got a higher c/a ratio with more trapped carbon in the lattice, where $\mathrm{c} \&$ a are the lattice parameters of the BCT cell. Hence hardness and strength increases with considerable amount of thermal stresses which in turn depends upon quenching severity.

Known for forming the highest level of strength in steel, the martensite structure is rarely used in untempered condition due to large number of internal stresses associated with the transformation, which causes the material to have low toughness [11-12]. However, low-temperature tempering is sufficient to reduce these stresses considerably without essentially changing the basic features of the martensitic structure.

Apart from the effect of tempering temperature, the strength of the martensitic structure is dominated by the carbon content and the $\left(\mathrm{M}_{\mathrm{s}}-\mathrm{M}_{\mathrm{f}}\right)$ temperature range $[13,14]$. In the case of low-carbon martensite, the martensitic units form in the shape of lath, grouped into larger sheaves or packets. Its substructure consists of high densities of dislocations arranged in cells. Mechanical properties and microstructure of medium carbon low nickel chromium steel is studied henceforth.

\section{Experimental Details}

The respective test specimens are prepared from $12.5 \mathrm{~mm}$ diameter as-received bar. Spectrometric analysis was done in order to investigate the chemical composition of the as-received bar. The standard specimen used in tensile test (as per ASTM standards) and hardness test is shown in figures 1 and 2 respectively. Specimens are turned in an engine lathe using single point HSS tool.

Three specimens each are tested for tensile properties in as-received, hardened, tempered at $250^{\circ} \mathrm{C}$ for 2 hours, tempered at $250^{\circ} \mathrm{C}$ for 4 hours, tempered at $450^{\circ} \mathrm{C}$ for 2 hours and tempered at $450^{\circ} \mathrm{C}$ for 4 hours. Three hardness readings are noted per specimen in each condition. The average of two consistent or closer readings is considered as the test results.

\subsection{Hardness Test}

The specimens are subjected to Rockwell Hardness Test. The values of hardness tabulated are obtained for a load of $100 \mathrm{~N}$, making use of a $1 / 16$ inch steel ball indenter.

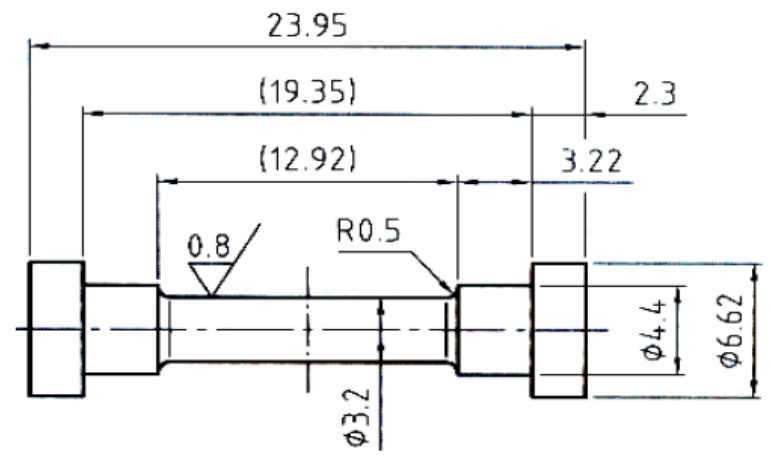

Figure 1. Tensile test specimen

\subsection{Tensile Test}

Tensile test is carried out using electronic tensometer with $20 \mathrm{KN}$ load cell and cross head speed of $2 \mathrm{~mm} / \mathrm{min}$. Test was performed as per ASTM standards and the plot of Load vs Percentage Elongation obtained from the instrument is analyzed for Ultimate Tensile Strength (Engineering UTS and True UTS), Percentage Break elongation and Percentage Peak elongation.

\subsection{Microstructural Test}

Microstructure specimens are polished with Emery paper starting from rough to smooth, from 600 microns to 100 microns, in the steps of 100 microns and etched with NITAL (solution of alcohol and nitric acid commonly used for etching steels). The metallurgical microscope is employed for microstructural analysis.

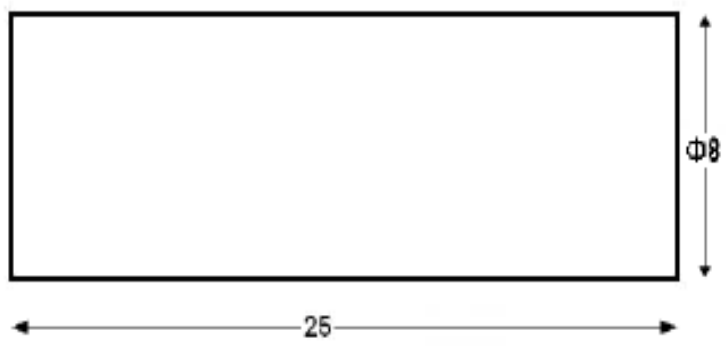

Figure 2. Hardness test specimen

\section{Results and Discussions}




\subsection{Effect on Hardness}

The As-received specimen which was in annealed condition has a Rockwell hardness value of HRC 51. On Normalizing there was a slight decrease in the hardness (HRC 50) owing to the refinement of grains and due to disappearance of any existing cementite. The Hardened specimen shows maximum value of hardness (HRC 68). This is owing to martensitic structure, known for its exceptional hardness. Figure 3 shows the variation in hardness values for different heat treated specimens. The hardness values as obtained on the tempered specimen clearly show that the drop in the hardness value is affected by both tempering temperature and tempering duration. As the tempering temperature and tempering duration increases, the softening process accelerates. This is due to the decrease in tetragonality of martensite in process of becoming a saturated phase. The main reason for the drop in hardness value on tempering is the rejection of carbon atoms from the martensitic matrix in the form of carbides [16].

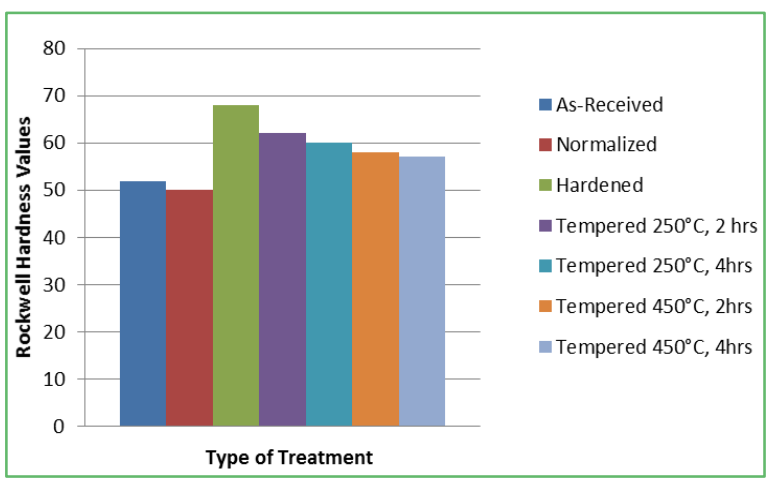

Figure 3. Hardness variation

\subsection{Effect of Heat Treatment on Mechanical Properties}

The mechanical properties of medium carbon low nickel chromium steel are highly sensitive to holding temperature and time. The normalized specimen has higher yield strength as well as Engineering Ultimate Tensile Strength when compared to the as-received specimen with a poor ductile cup and cone type fracture. The hardened specimen has the highest level of strength. Figure 4 shows the Load v/s \% Elongation plot for hardened specimen. This can be explained by the phase transformation that the steel undergoes on quenching from the hardening temperature. The high temperature structure i.e Austenite (FCC lattice) changes to Martensite (BCT lattice). As soon as austenite is quenched below the $M_{s}$ temperature the lattice transforms to a BCT structure. However the chemical composition of the structure still remains the same. This is why the martensitic structure is called a Supersaturated Solid Solution. Due to the very high cooling rates employed during quenching the carbon atoms present inside lattice cannot diffuse out and due to this entrapped carbon martensitic structure has a distorted BCT structure. It has high strength values but the structure has residual stresses that inhibit its use. On tempering the steel it is seen that there is a decrease in the strength values. While ageing (soaking) at the isothermal temperatures for tempering, the carbon atoms diffuse out of the supersaturated BCT lattice of the martensite and form carbides. Hence height of BCT martensite with lower height of BCT cell is soft. This drop in the value proceeds with an increase in holding temperature as well as holding time but effect of the former is more significant. There is an increase in toughness value and a drop in strength and hardness. This is a result of precipitation of $\mathrm{Fe}_{2.4} \mathrm{C}$ ( $\mathcal{E}$ - Carbide) [15]. Figure 5 shows Load $\mathrm{v} / \mathrm{s} \%$ Elongation plot for the specimen tempered at $250^{\circ} \mathrm{C}$ for 2 hours. Figure 6 and 7 shows the strength values respectively for different test specimen.

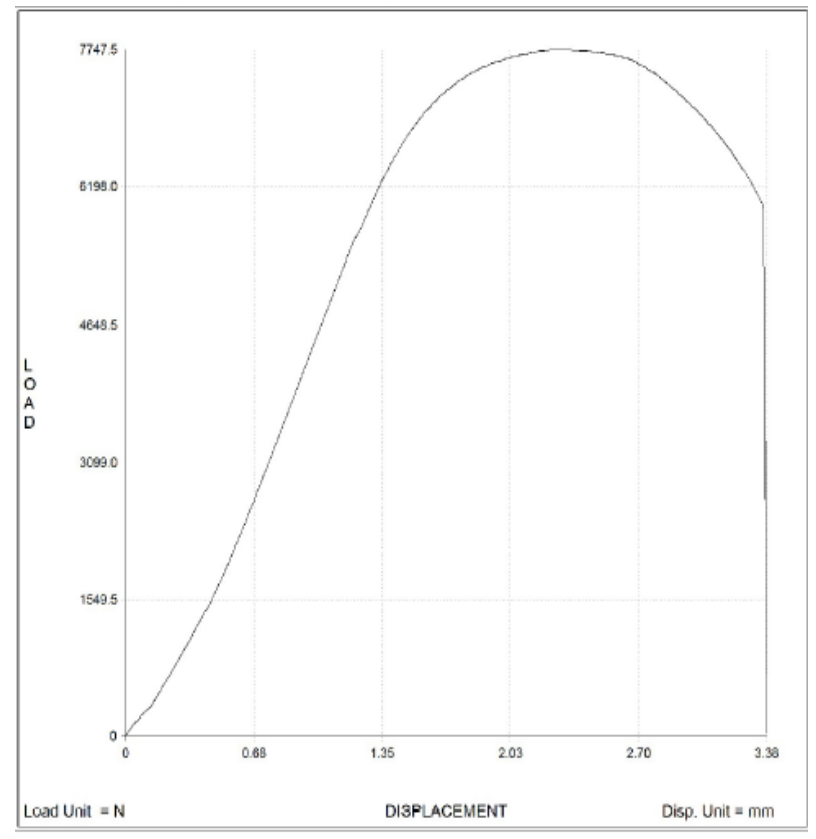

Figure 4. Load vs \% Elongation Plot (Hardened specimen)

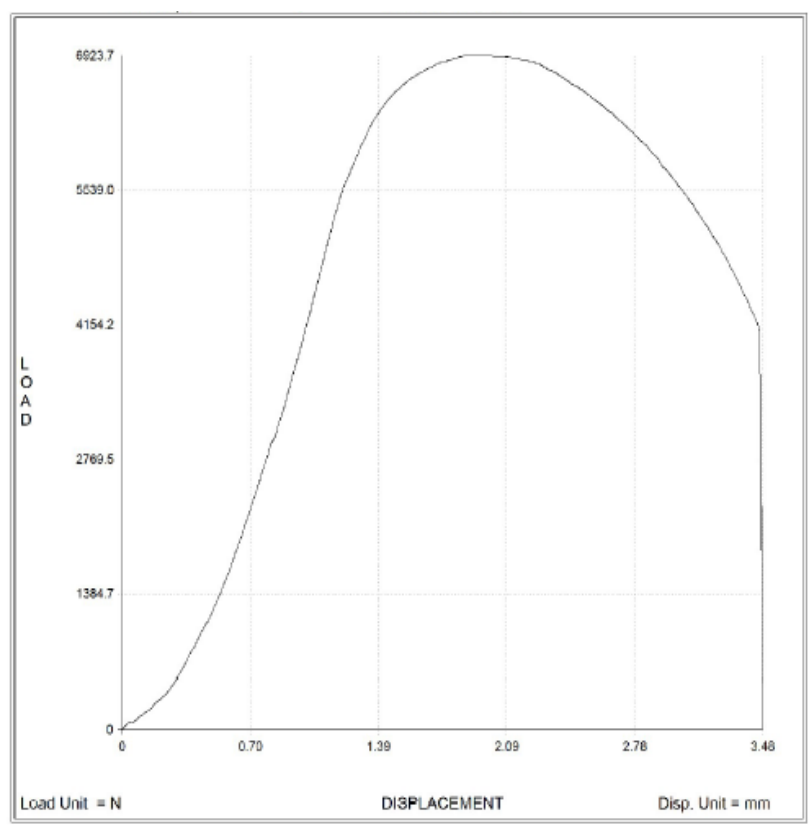

Figure 5. Load vs \% Elongation Plot (Tempered Specimen)

Figure 8 and 9 shows ductility values of heat treated specimens. As the tempering temperature increases, ductility 
increases. As tempering duration increases ductility increases at the lower temperature. But a surprising result is seen at $450^{\circ} \mathrm{C}$ where when the tempering duration increases, the ductility decreases. This may be due to the transformation of Epsilon Carbide phase $\left(\mathrm{Fe}_{2.4} \mathrm{C}\right)$ of bainite into cementite phase.

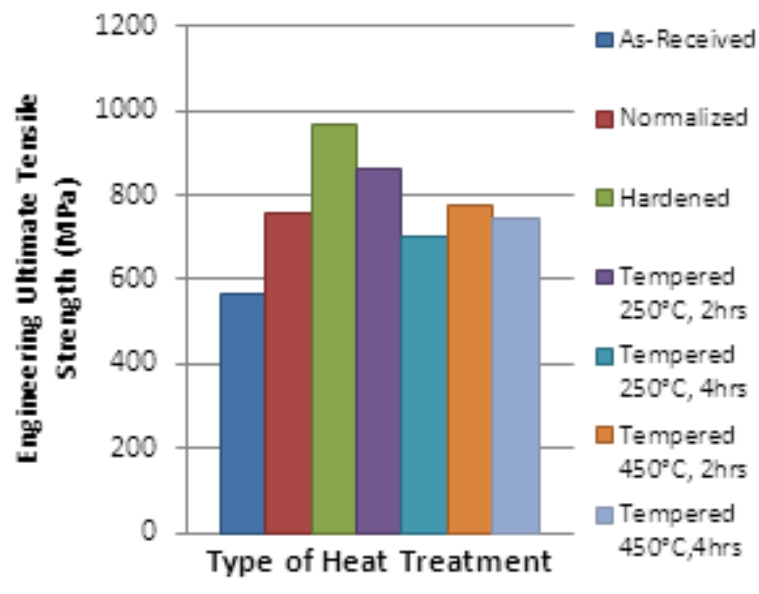

Figure 6. Engineering UTS variation

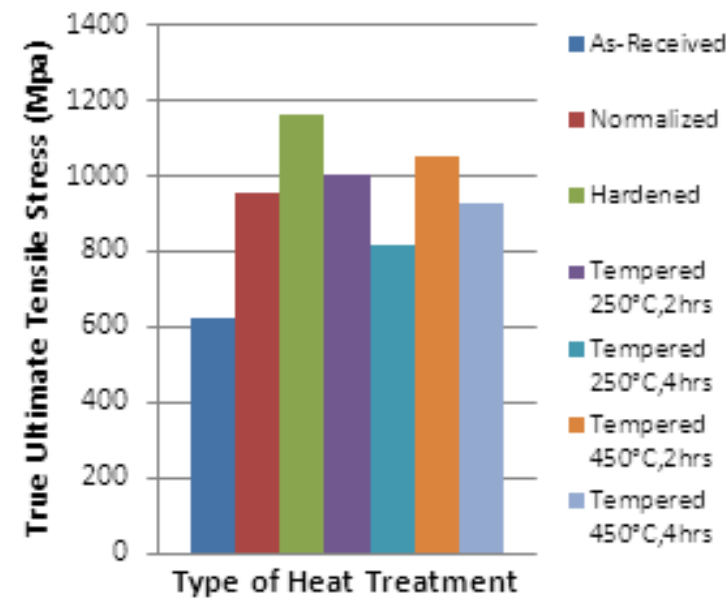

Figure 7. True UTS variation

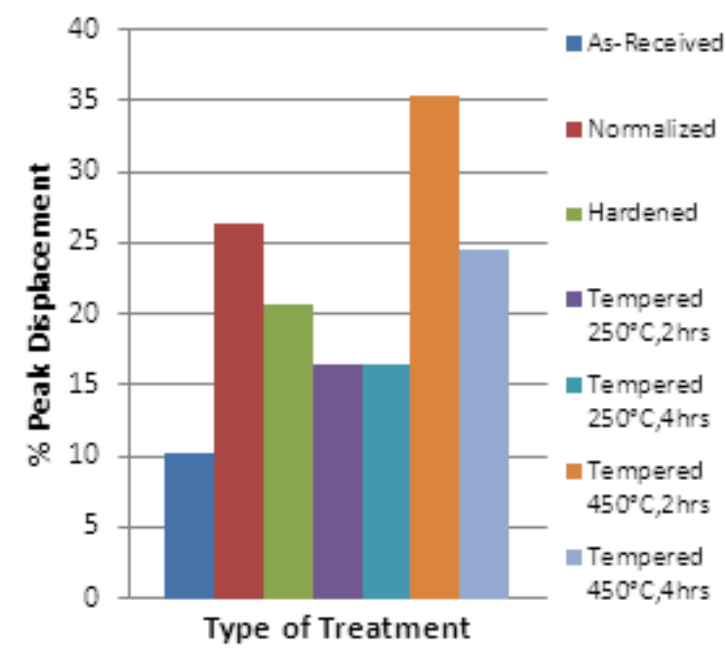

Figure 8. \% Peak Displacement variation

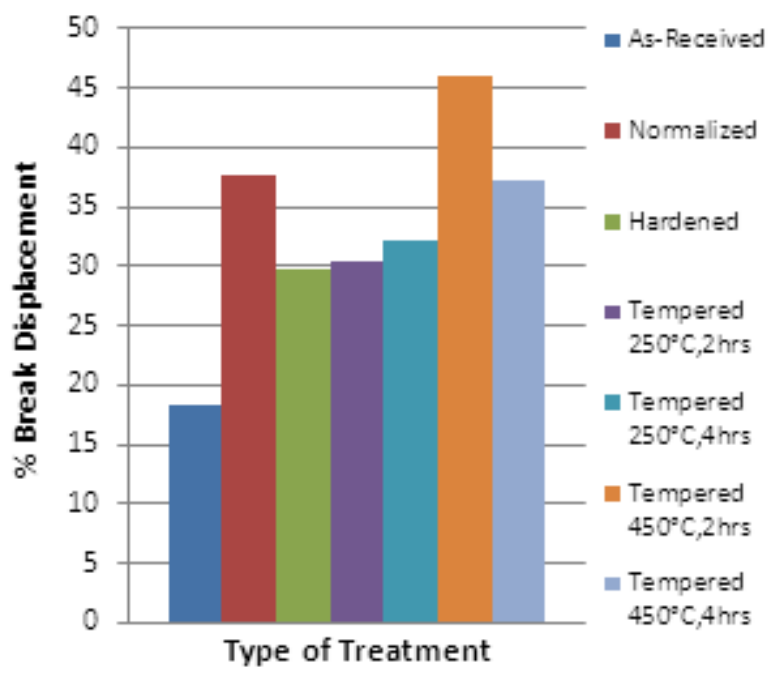

Figure 9. \% Break Displacement variation

\subsection{Effect of Heat Treatment on Microstructure}

The as-received steel microstructure study showed well defined pearlitic colonies with proeutectoid ferrite along grain boundaries. The microstructure confirmed that as-received steel is air cooled. Figure 10 shows microstructure of as-received steel (Magnification-200X). The Normalized one on the other hand showed finer/refined grains with distinct grain boundaries with proeutectoid ferrite present along it. No proeutectoid cementite phases are observed. Figure 11 shows the microstructure for the normalized steel (Magnification-500X). The specimen which was hardened (after normalizing) shows band like structure indicating the presence of dislocated martensitic laths. Figure 12 shows microstructure of hardened steel (Magnification-200X). Microstructure study done on the specimen which was tempered at $250^{\circ} \mathrm{C}$ for 2 hours showed the precipitated carbides along with the martensitic laths.

On the other hand, the one tempered for 4 hours at $250^{\circ} \mathrm{C}$ showed grown martensitic laths along with still higher precipitated carbides in the martensitic matrix. Figure 13 shows the microstructure of specimen tempered at $250^{\circ} \mathrm{C}$ for 4 hours (Magnification-500X). Similar observations were made on the specimen tempered at $450^{\circ} \mathrm{C}$ for 2 hours. The only difference in the observation was that the martensitic laths were larger and precipitated carbides were more. As for the tempered specimen $450^{\circ} \mathrm{C}$ for 4 hours, martensitic laths were bigger than those in previous case and also there was an increase in the precipitated carbides. The surprising result of decrease in ductility at $450^{\circ} \mathrm{C}$ on prolonged duration might be the transformation of Epsilon carbide $\left(\mathrm{Fe}_{2.4} \mathrm{C}\right)$ into cementite $\left(\mathrm{Fe}_{3} \mathrm{C}\right)$ phase because cementite phase has lesser ductility compared to epsilon carbide phase. 


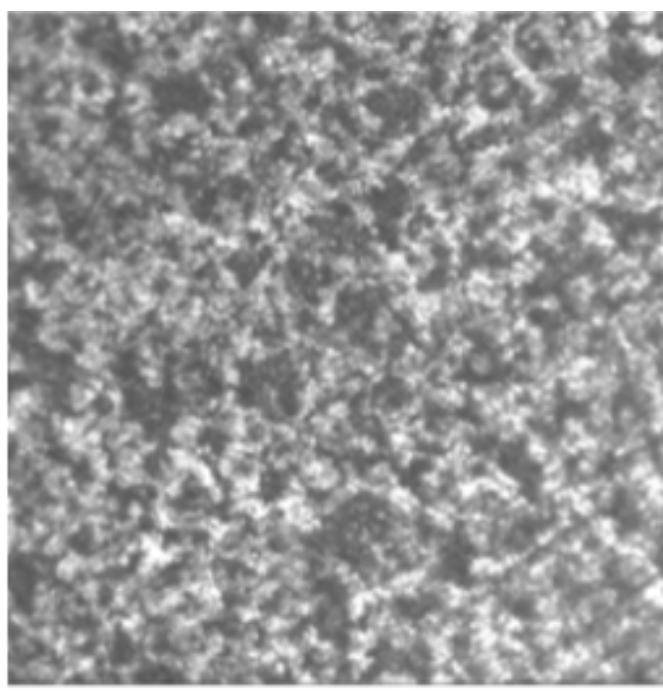

Figure 10. Microstructure As-Received Specimen (Magnification-200X)

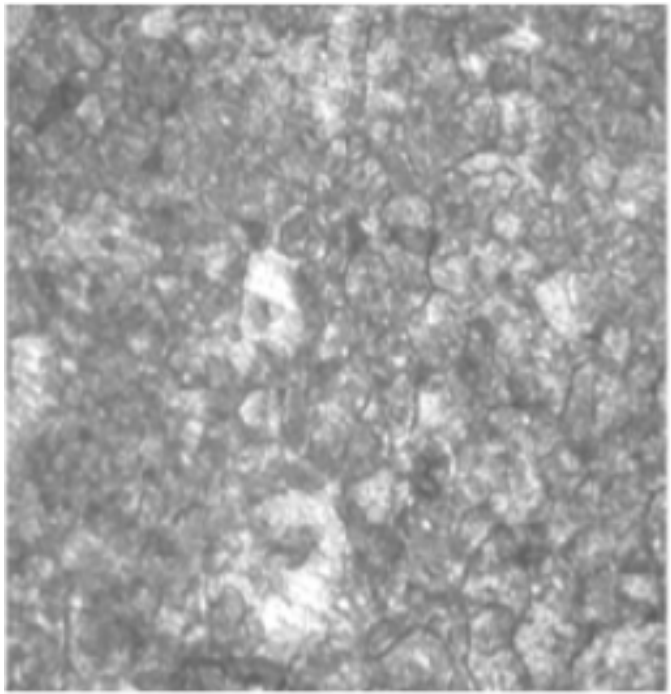

Figure 11. Microstructure of Normalized Specimen (Magnification-500X)

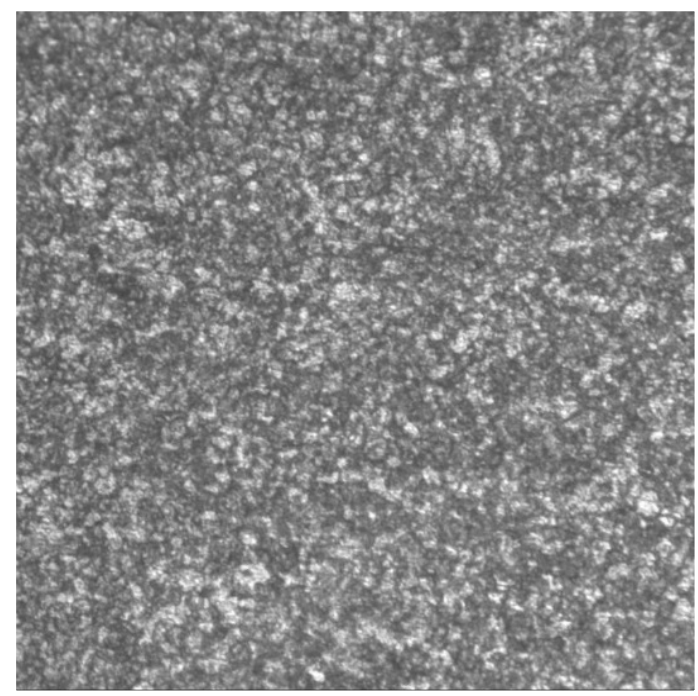

Figure 12. Microstructure of Hardened Specimen (Magnification-200X)

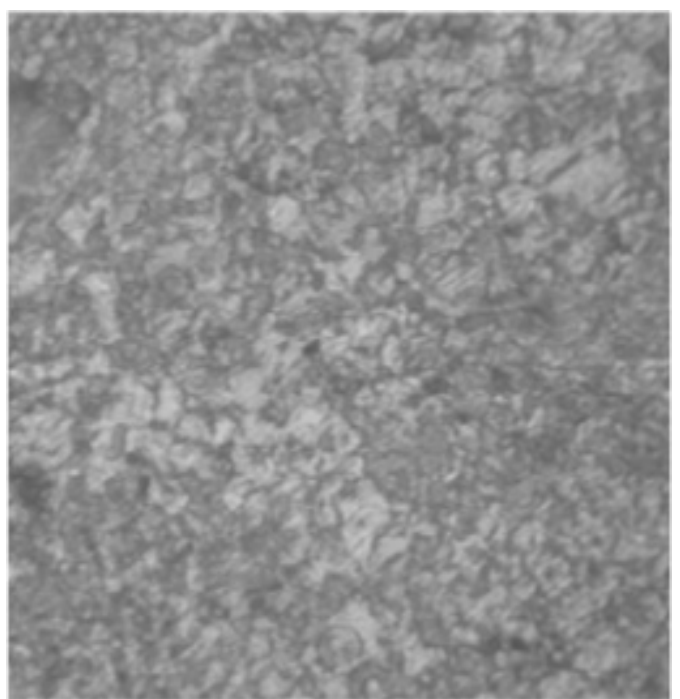

Figure 13. Microstructure of Tempered Specimen (Magnification-500X)

\section{Conclusions}

- The selected steel is responding perfectly to all heat treatments performed. The results obtained is in par with the expectations, still the following observations may be evolved during the analysis of the results.

- The mechanical properties of medium carbon low nickel chromium steel are highly sensitive to holding temperature and time. The Hardened specimen shows highest values of Ultimate Tensile Strength.

- Hardening Heat Treatment gives ultimate hardness.

- Tempering effect is a function of holding time and holding temperature but effect of former is more effective.

- Microstructure of as-received and normalized condition reveal the presence of fewer colonies of pearlite (refined grains) with small regions of proeutectoid ferrite.

- Microstructure study on hardened steel shows band like structures which are dislocated martensitic laths.

- Tempered specimen shows precipitation of carbides during ageing of supersaturated martensite.

\section{REFERENCES}

[1] Sarwar M, Priestner R., 1996, "Influence of ferrite-martensite microstructural morphology on tensile properties of dual-phase", Journal of Materials Science, Vol 31, pp 2091-2095.

[2] Erdogan M, Priestner R., 2002, "Effect of martensite content, its dispersion, and epitaxial ferrite content on Bauschinger behavior of dual phase steel", Journal of Materials Science Technology, Vol18, pp 369-376. 
[3] Anand Prakash Modi, 2007, "Effects of microstructure and experimental parameters on high stress abrasive wear behaviour of a 0.19 wt \% Carbon dual phase steel", Tribology International Journal, Vol 40, pp 490-497.

[4] Chang P., 1984, "Temper-aging of continuously annealed low carbon dual phase steel", Metal Transformation, Vol15A, pp 73-86.

[5] Hardness Prediction Model for En Grade Steels Subjected to Different Heat Treatment Processes S. Jyothirmai, I. Aparna Devi, I. Sudhakar and R. Ramesh. Advanced Materials Manufacturing \& Characterization Vol4 Issue 2 (2014)

[6] K.J IRVINE, Development of High Strength Steels, 1962 ,J. Iron Steel Inst. 12 (1962) 620-629.

[7] Gunduz S, Demir B, Kacar R., 2008, "Effect of aging temperature and martensite by volume on strain aging behavior of dual phase steel', Iron making and Steel making, Vol 35, pp 63-68.

[8] Yan-qiu Zia, Wei-min Liu \& Qun-Ji Xue, 2005, "Comparative study of the tribological properties of various modified mild steels under boundary lubrication condition", Journal of Wear, Vol 38

[9] Anijdan SHM, Vahdani H., 2005, "Room-temperature mechanical properties of dual phase steels deformed at high temperatures”, Materials Letter, Vol 59, pp 1828-1830.
[10] "Thermal treatments \& characteristics study on unalloyed structural (AISI 1140) steel” S. S. Sharma, P. R. Prabhu, Rajagopal Chadaga, World Academy of Science, Engineering and Technology 702010

[11] C.L. Briant, S.K. Banerji, Tempered martensite embrittlement in phosphorus doped steels, Metall. Trans. 10A (1979) 1729-1739.

[12] R.M Horn, R.O. Ritchi, Mechanisms of tempered martensite embrittlement in low alloy steel, Metall. Trans. 9A (1978) 1039-1047.

[13] K. Shimizu, Z. Nishiyama, Electron microscopic studies of martensitic transformation in iron alloys and steels, Metall. Trans. 3A (1972) 1055-1066.

[14] S.K. Das, G. Thomas, Structure and mechanical properties of Fe-Ni-Co-C steels, Trans. ASM 62 (1969) 659- 668.

[15] Woei-ShyanLee ,Tzay-Tian $\mathrm{Su}$ Journal of Materials Processing Technology 87 (1999) 198-206

[16] Influence of Tempering Temperature on Both the Microstructural Evolution and Elemental Distribution in AISI 4340 Steels Nam Suk Lim1, Chan Woo Bang1, Sanjeev Das1, Hyun Woo Jin3, Raghavan Ayer3, and Chan Gyung Park1,2,* Met. Mater. Int.,Vol. 18, No. 1 (2012), pp. 87 94 